\title{
画像処理装置を利用した着色物の二次元分光測色
}

\author{
大阪市立工業研究所田川由利香・上田 充夫・平嶋 恒亮 \\ ミノルタカメラ高柣研究所 政木 康生*
}

\section{TWO DIMENSIONAL SPECTRAL COLOR ANALYSIS OF COLORED MATERIALS UTILIZING COMPUTER IMAGE ANALYZING SYSTEM}

\author{
By Yurika Tagawa ${ }^{* 1}$, Mitsuo Ueda ${ }^{* 1}$,Yasuo Masaki ${ }^{* 2}$, and Tsuneaki Hirashima ${ }^{* 1}$ \\ *1 Osaka Municipal Technical Research Institute, Joto-Ku, Osaka, 536 Japan \\ *2 Minolta Camera Co., Ltd., Takatsuki Lab., Sakuramachi, Takatsuki, 569 Japan
}

\begin{abstract}
The methods to analyze the color of dyed or printed materials utilizing computer image analyzing systems were studied. Spectral reflectance curves and tristimulus values of the samples could be obtained as two dimensional data from the image of the sample. The reflection image of the sample was fil. tered and spectrally divided with 20 types of interference monochromatic glass filters $(20 \mathrm{~nm}$ intervals, $400-780 \mathrm{~nm})$ to 20 divisions of monochromatic images. Each monochromatic image was recorded by video camera, digitalized, and stored on the computer memories. From the images on the memories, spectral reflectance curve and CIE-XYZ tristimulus values at any point of the sample could be obtained with high accuracy. The technique could be applied to the quantitative analysis of the colorant absorbed on a solid substrate. The image of the sample formed by monochromatic reflection was converted to that formed by $\mathrm{K} / \mathrm{S}$ values by computer calculation using the Kubelka-Munk equation. Since an intensity at any point in the $\mathrm{K} / \mathrm{S}$ image could be related to the density of colorant at the corresponding point of the sample, the in tegration of the intensities of $\mathrm{K} / \mathrm{S}$ image over enfire surface represents the total amount of colorant on the sample. Some examples of the method were demonstrated.
\end{abstract}

(Received January 22, 1990)

\section{1. 腥 言}

着色物の色彩管理あるいは色評価は現在でも多くの場 合肉眼に頼っている。しかしながら，肉眼による色評価 はサンプルの大きさ, 光源光量, 背累色, サンプル間距 離などによる色覚の変動を避けることができず，往々に して大きな評価誤差を導くことがある。また、判定還境 を極めて䇴密に規定しなければならない上に，判定者に は十分な熟練が要求される。

このような現状から，近年，着色物の色評価を譏器に

*現在の所属: (株)画像工学研究所 T639-02 奈良県北葛城郡香芝町

*2 Present address: Imaging Technology Laboratory Co., Ltd., Kashiba-cho, Kitakatsuragi-gun, Nara, 639-02 Japan
よって行なおうとする傾向が顕著になり，コンピュー夕 カラーマッチングや染料溶液自動調液システムの開発な ど機器測色による色材管理方法が積極的に検討され，導 入されている $(1-4)$ 。また，寺主[5] は実際に機器計測 によって色彩管理を行う上で非常に重要な問題として指 摘される、人間の色覚と機器による理論的な測色值との 差異について詳細な研究を行い，これらの差異を補完し た新しい独自の表色系として $\mathrm{HC}^{*} \mathrm{~B}^{*}$ 表色系を提案し，

機器による色彩管理の実用化への適応を広げた。

さて,このような機器測色の普及に伴い, 多種多様な 実際の着色物に対応できる睁色機器が望まれるようにな った。しかし, 従来の機器では比較的広い試料面積を必 要とし，色相や色濃度が勾配をもって変化している試料 などについては適用か困難である。また，多種にわたる 着色物の中で測色機器のメカニズム上利用できない場合 
も数多く見られる。したがって，これらの諸問題を解決 し，かつ最近のニーズに応える必要性から，よりミクロ な領域で，しかも二次元的な色彩変化にも対応できる，

より適用範囲の広い測色機器の開発が望まれる。

そこで，我タはコンピュータ画像処理装置を応用して 測色を行なう試みを行なってきた。画像処理装置での色 彩計浿が可能となれば，色彩変化を二次元的に解析でき るので，複数の色彩が複雑に入り組んだ染色物や，色が 微妙に变化するサンプルなど，これまで既存の色彩計測 機器では不可能であっだサンプルについても機器による 測色の適用範囲が著しく应大すると考えられる。

すでに前報(6)では，ハンター型三剌激值直読式色彩 計の基本原理を応用した画像測色方法について検討し た。すなわち画像処理装置のモノクロビデオカメラの前 にCIE-XYZ 三刺激値曲線に対応した三枚のガラスフィ ルターを順次取り付けて，各フィルターの分光感度曲線 に適合した分光画像をメモリーに取り迟み，その各画像 の濃度值(光量值)から試料の三刺激值 XYZをその位置 情報とともに一括して得る方法を検討した。

本報では，さらに精度が高く、より応用籍囲が広い分 光反射率測定式画像測色システムについて述べる。これ は従来の反射分光光度計の基本原理を応用したもので, モノクロビデオカメラの前に干渉フィルターを装着し, 可視光領域 $(400-780 \mathrm{~nm})$ について，各波長ごとに分光 された反射光画像を画像処理装置のメモリーに記憶させ る。これらの画像が持つ濃度值情報を総合して, 試料画 像の分光反射スベクトルをその位置情報とともに得て, さらには，三刺激值 XYZを得ようとするものである。 この方法では, 非接触で, 取り込んだ試料の任意の位置 の分光反射スベクトルを得ることができる。

さらに，本システムの応用例として，画像測色システ 厶を用いた固体基質上に吸着した色素の定量分析をおこ なった。この定量方法を利用すると，サンブルをビデオ カメラに取り込むだけで色素量が求められるので，従来 のような色素の溶媒抽出の必要は無く，複数の色素が同 一基質上に混在するような場合でも目的の色素だけを画 像処理によって任意に取り出し色素定量ができる。薄層 クロマトクラフィ法による色素の定量にも有効に利用で きる。

このように，本システムは測色以外にも応用範用が広 く，極めて興味深い方法である。

\section{2. 実跧}

\section{1 画像処理装犆}

使用した画像処理㳖䈯は(株)ピアス製の PIAS-IIE お

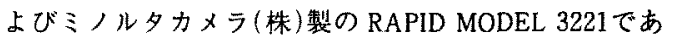

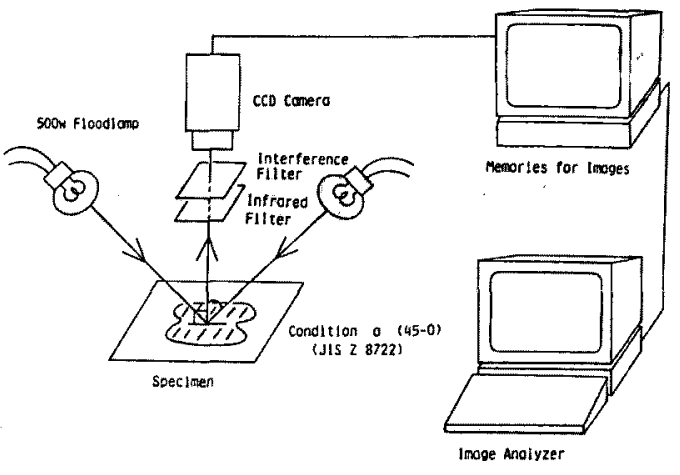

Fig. 1. Schematic diagram of the image analyzing system.

る。PIAS-IIE はモノクロ画像 $(512 \times 512$ 画素) 4 画面の オンメモリー記憶が可能で画像湢度は64階調である。一 方, RAPID MODEL 3221 は20画面 $(512 \times 512$ 画素)が才 ンメモリーで記憶でき，画像浱度は256階調に分解され る。いずれの装䈯も CCD ビデオカメラによって画像入

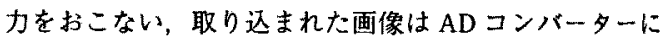
よってデジタル化された後，画像処理装埴のメモリーに 記憶され各種の处理がなされる。本システムの全体圆を 図1に示す。

\section{2 照明およひ受光の条件}

画像入力の際の照明および受光の条件はJIS Z 8722-1981(物体色の測定方法)条件 a の45度照明，0度 受光方式(45-0方式)を用いた。光源には色温度 $3150 \mathrm{~K}$ の $500 \mathrm{~W}$ タングステンフラッドランプ(東芝)を 2 灯使用し た。

\section{3 光学ガラスフィルター}

分光した画像を得るための光学フィルターには日本真 空光学(株)製の干渉フィルターを400-780nm の波長笙 囲で20nmごとに合計20枚使用した。これらはいずれも 二次干涉を用いた金属干涉フィルターで，中心波長の最

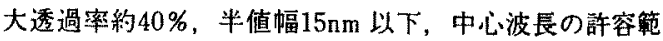
囲は土3 nmである。これらを画像入力の際に一枚ずっ モノクロビデオカメラのレンズの前に装着した。さら に，CCDビデオカメラは近赤外領域にまで高い受光感 度をもっているので，近赤外光の透過を防ぐために IRQ-80(東芝)シャープカットオフ・フィルター[7]を 併せて使用した。

\section{4 洊定方法の概要}

画像処理装置は反射光画像をビデオカメラで取り込ん で，その画像を構成する画素の位置と反射光量值を画像 メモリーに保存し，種々の処理を行なうものである。通 常の場合，取り込まれる試料反射光は分光されていない 
ので,メモリーに保存された画像には反射光の波長や色 彩に関する正確な情報はない。(カラーカメラによって 取り这まれた色彩は RGB 表色系で表現されるが，RGB 表色系特有の $500 \mathrm{~nm}$ 前後の負量を無梘しているため に，取り込まれた画像には正確な色彩情報はない。)そこ で，本システムでは画像に正確な色彩情報を持たせるた めに画像入力の際，干涉フィルターによって画像をあら かじめ分光してから取り这む方法を採用した。まず，入 カビデオカメラの前に赤外カットフィルターと400nm の干涉フィルターを取り付け，試料の $400 \mathrm{~nm}$ 画像を取 り这み画像メモリーあるいは外部記憶装置に保存した。 次に干涉フィルターを420nm に交換し，同様に $420 \mathrm{~nm}$ の画像をとり込み，以下，順次 $780 \mathrm{~nm}$ まで分光画像を 取り込んだ。これらすべての画像について同じ位置にあ る画素に注目し，その画像濃度值を波長に対して走查す れば，その画像位置の見かけの可視領域の分光反射スペ クトル(20nm 間隔)を得ることができる。そして，絶对 反射率既知の白色標準の画像濃度值との比をとることに よって，画像各位置の各波長における絶対分光反射率を 求めることができる。(サンブル画像と白色標準の画像 の比を取ることによって，ビデオカメラに使用されてい るCCD の個々の感度特性の違い圭校正することができ る。測定方法のシステムフローを图 2 に示した。

色彩のパラメータは試料の着目画素の分光反射率曲楾 から次に示す JIS Z 8701 の XYZ 表色系による表示方 法[8]に従って三刺激值 XYZ 求めた。

$$
\begin{aligned}
& \mathrm{X}=\mathrm{K} \int_{380}^{780} \mathrm{~S}(\lambda) \overline{\mathrm{x}}(\lambda) \mathrm{R}(\lambda) \mathrm{d} \lambda \\
& \mathrm{Y}=\mathrm{K} \int_{380}^{780} \mathrm{~S}(\lambda) \overline{\mathrm{y}}(\lambda) \mathrm{R}(\lambda) \mathrm{d} \lambda
\end{aligned}
$$

Successive insertion of the filter. 400-780nn input of the monochromatic images of white standard memorization of standard data on computer menories $I_{0 \lambda, 1,5} \quad \lambda: 400-780,1,5: 0-511$

successive insertion of the f1lter. $400-780 \mathrm{nal}$ input of the monochromatic images of sample menorization of sample data on computer menories $I_{\lambda, 1,5} \lambda: 400-780,1,5: 0-511$

specification of the area to analyze reading of digitalized intensitles in the area from memories calculation of spectral reflectances

$R_{\lambda, 1, j} * k_{\lambda, 1, j}\left(l_{\lambda, 1, j}\right) /\left(t_{0 \lambda, 1, j}\right)$ $\lambda: 400-780,1, j: 0-511$ calculation of tristimulus values

output of the reflection spectra and tristimulus values

Fig. 2. Flow diagram of two dimensional spectrocolorintry.

$$
Z=K \int_{380}^{780} S(\lambda) \bar{z}(\lambda) R(\lambda) d \lambda
$$

ここで, $S(\lambda):$ 光源の分光分布

$\overline{\mathrm{x}}(\lambda), \overline{\mathrm{y}}(\lambda), \overline{\mathrm{z}}(\lambda): \mathrm{XYZ}$ 系に基つく等色関数

$\mathbf{R}(\lambda)$ : 分光反射率分布

$\left.\mathrm{K}=100 / \mid \int_{380}^{780} \mathrm{~S}(\lambda) \overline{\mathrm{y}}(\lambda) \mathrm{d} \lambda\right\}$

$\lambda:$ 波長 $(\mathrm{nm})$

\section{3. 実䜽結果および考察}

\section{1 画像入力装異の入射光直線性}

画像処理装置の画像入力部(CCD ビデオカメラお゙よ び, A-D コンバータ)の入力光量と表示デジタル化濃度 値との間にどの程度の直線関係があるかをしらべた。画 像処理装置 PIAS-IIEについて，種々の明度のグレース ケールを用い，その反射光画像のデジタル化光量値(画 像中央 $70 \times 70$ 画素の平均值)をグレースケールの反射率 (420-700nm の波長領域に招ける値)に対してプロット したのが図 3である。この際、ビデオカメラの CCD は その性質上，入力光量がゼロでも素子自体の暗電流によ る出力電圧が諗められるので，測定のつどゼロ光量画像 を別に取り込み，それらの差画像の濃度值をプロットし たものである。したがって，CCD暗出力の画素間のば らつきは相殺されている。図 3 からわかるようにダレー スケールの反射率と取り込まれた画像のデジタル化濃度 值との間には良好な直線関係が認められる。このこと は，画像入力装置は光の取り込み黨に比例した正確なデ ジタル化濃度值を与えることを示すものである。同㥞の 検討を西像周辺部でも行なった。画像周辺部において は，直楾性は良かったものの，中心部に比べて若干の感

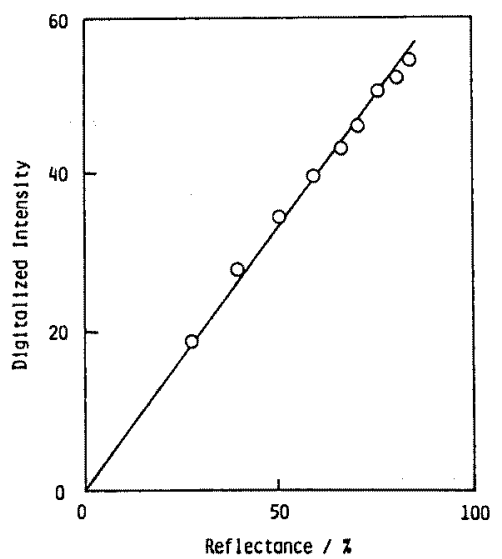

Fig. 3. Relation between reflectances of gray scales and their average digitalized intensities of the images. 
度低下（直線の傾きの低下）が認められた。これは CCD 自体の性啠に起因するものではなく，ビデオカメラレン ズの周辺光量の低下および照明の周辺輝度の低下による むのと考えられる。したがって，画像全体について二次 元的に濃度值を比較するような場合には，画像位固ごと の入力感度の補正を行なわねばならない。幸い，本研究 では反射率を求めるために標準白板の対照反射光量と測 定試料からの反射光量との比をとることになるので，画 像位埴ごとの感度の違いなどが相殺される。なお， RAPID MODEL 3221に関しても, 入射光量とデジタル 化光量值との間に同㥞の直線性が認められた。

\section{2 分光反射率の测定}

入カビデオカメラの前に400-780nm の波長範囲で $20 \mathrm{~nm} こ ゙ と の 20$ 枚の干渉フィルターを順次取り付け，取 ク込んだ20種の試料画像を画像メモリーに保存した。画

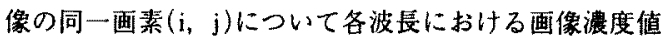
$I_{\lambda, i, j}(\lambda: 400-780 \mathrm{~nm}, i, j: 0-511)$ と絶対反射率既 知の白色標染の画像濃度値 $\mathrm{I}_{\mathrm{O} \lambda \text {. } \mathrm{i.j}}(\lambda: 400-780 \mathrm{~nm}, \mathrm{i}$, $\mathrm{j}: 0-511)$ との值加式 1 を用いて画像各位置の各波 長における絶対分光反射率を求めることができる。

$$
\mathrm{R}_{\lambda, i, j}=\mathrm{k}_{\lambda, i, j} \cdot\left(\mathrm{I}_{\lambda, \mathrm{i}, \mathrm{j}}\right) /\left(\mathrm{I}_{O \lambda, \mathrm{i}, \mathrm{j}}\right)
$$

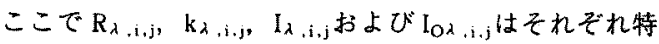
定画素( $i ， j)$ ，特定波長 $(\lambda)$ における絶対反射率，测定 值を相対反射率から絶対反射率へ変換するための係数 (白色標準の絶対反射率の逆数)，試料の画像濃度值拉よ び白色嫩準の画像濃度值である。

得られた試料の絶対反射率 $R_{\lambda . i, j}(\lambda: 400-780 \mathrm{~nm}$,

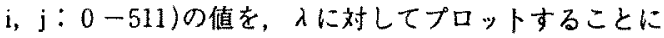

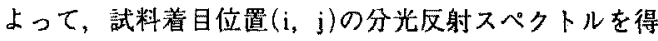
ることができる。

着色物のモデルとして赤, 黄, ピンク，青の 4 種類の 着色ケント紙を試料に用い，以上のようなお法によって

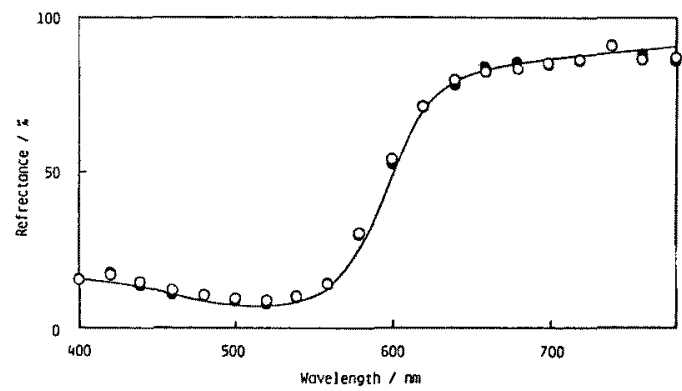

Fig. 4. Spectral reflectance curve of red-colored Kent paper determined by the image analyzing system: (O) average reflectance of $4 \times 4$ pixels in the center of the image; (Overage reflectance of $4 \times 4$ pixels in the right below of the image; (-) spectrophotometer.

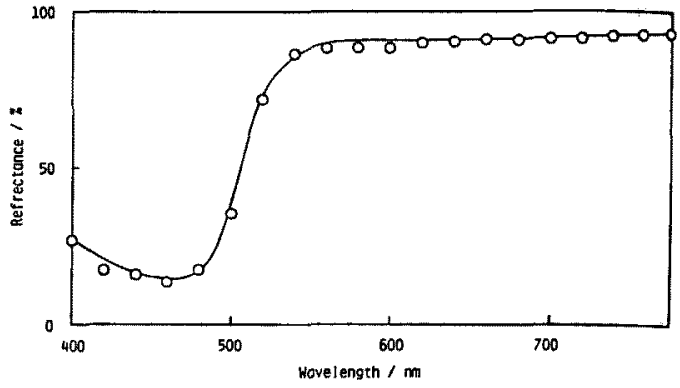

Fig. 5. Spectral reflectance curve of yellow-colored Kent paper determined by the image analyzing system: (O) average reflectance of $4 \times 4$ pixels in the center of the image: $(\longrightarrow$ spectrophotometer.

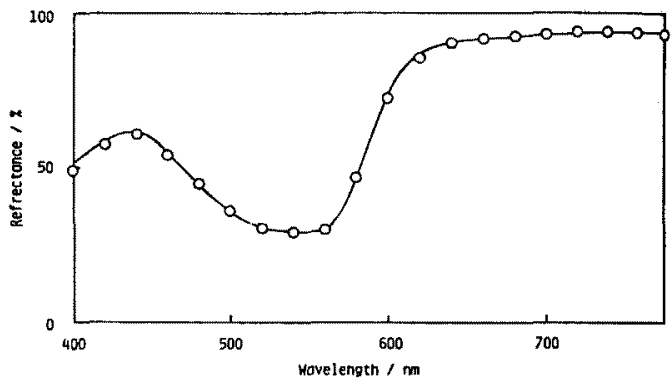

Fig. 6. Spectral reflectance curve of pink-colored Kent paper determined by the image analyzing system: 10 ) average reflectance of $4 \times 4$ pixels in the center of the image; $(\longrightarrow$ ) spectrophotometer.

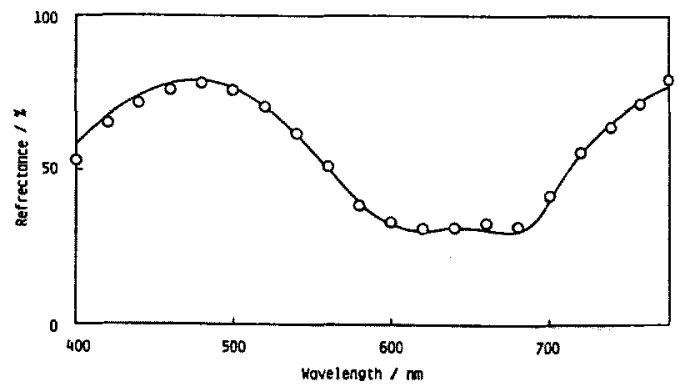

Fig. 7. Spectral reflectance curve of blue-colored Kent paper determined by the image analyzing system: (O) average reflectance of $4 \times 4$ pixels in the center of the image; $(\longrightarrow$ ) spectrophotometer.

その絶対分光反射スペクトルを測定した。ミノルタ製 RAPID 画像処理システムを用いて得たスペタトルを図 4-7に示した。スペタトル図中の各プロットがそれぞ れ本システムによって得た值で，実線は(株)島津製作所 MPS-2000反射分光光度計カラーパックシステムによっ て得た絶対反射スペクトルである。図4の2 種類のプロ 
ットは画像中央部 $4 \times 4$ 画素，およひ画像右下部 $4 \times 4$ 画素における画像濃度の平均值から得た反射率值を比較 のために示したものである。図4-7からわかるよう に，本画像測色システムで得た反射スペクトルは反射分 光光度計によって得た做と極めて良い一致を示して扔 り、このシステムが十分な精度の絶対反射スペクトルを 与えることを示すものである。また，図4からわかるよ うに、画像中央部での䁚定値と画像周辺部(右下)での値 との比較でも良い一致が得られており，このシステムの 画像全領域における富い測色精度を示晙するものであ 方。

本システムによって得た反射率の各值から IIS Z 8722 に規定された「物体色の測定方法」に準起して，C光源 2 度視野における三刺激值 $X, Y, Z$ を求め，分光光度 計により得た値とともに表】に示した。表1から明らか なように，本システムは十分な精度の測色値を与えるこ とがわかる。

Table 1 Tristimulus Values of Colored Kent Papers Obtained by Image Spectrocolorimetry and Conventional Spectrocolorimetry. (Illuminant C, $2^{\circ}$ Visual Field)

\begin{tabular}{lcccccc}
\hline \multirow{2}{*}{$\begin{array}{l}\text { Color of } \\
\text { Kent paper }\end{array}$} & \multicolumn{3}{c}{$\begin{array}{c}\text { Image spectro- } \\
\text { colorimetry }\end{array}$} & \multicolumn{3}{c}{$\begin{array}{c}\text { Conventional } \\
\text { spectrocolorimetry }\end{array}$} \\
\cline { 2 - 8 } & $\mathrm{X}$ & $\mathrm{Y}$ & $\mathrm{Z}$ & $\mathrm{X}$ & $\mathrm{Y}$ & $\mathrm{Z}$ \\
\hline Blue & 44.8 & 52.5 & 85.9 & 45.0 & 52.5 & 88.6 \\
Yellow & 71.1 & 74.9 & 19.9 & 73.8 & 79.8 & 21.8 \\
Pink & 59.0 & 44.4 & 63.1 & 59.9 & 44.8 & 63.9 \\
Red & 38.7 & 25.6 & 15.4 & 36.8 & 22.8 & 13.2 \\
\hline
\end{tabular}

\section{3 基筫上の色秦の画像定量}

本システムが画像全体に扔いて正確なスペクトル反射 率値を与えることを利用して，布や紙などの基質上に存 在する色素の量を画像の濃度值から定量する試みを行な った。

基質上の色素の黨はKubelka-Munk[9]によって理諭 的に遒き出された式 2 に示すような $\mathrm{K} / \mathrm{S}$ 值と比較的よ い直線関係にあることが知られている。

$\mathrm{K} / \mathrm{S}=(1-\mathrm{R})^{2} / 2 \mathrm{R}$

ここで，K/S は色素の量を表すパラメー夕，Rは着色 表面の搪散反射率を示す。

したがって，本システムを用いた測定に执いて，特定 の画像位置 $\mathrm{i} ， \mathrm{j}$, 波長入における搪散反射率 $\mathrm{R}_{\lambda . j, j}$ 知 れば式 3 を用いて，反射光によって描かれた通常の画像

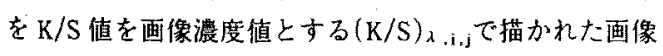
へと，システム内で演算変換することができる。

$$
(K / S)_{\lambda, i, j}=\left(1-R_{\lambda, i, j}\right)^{2} / 2 R_{\lambda, i, j}
$$

そして，得られた画像の各位置の濃度值は，それぞれ試 料上の色素濃度に対応することになるので，各西像位置 の画像濃度を取り出せば，その位置の色素濃度の $\mathrm{K} / \mathrm{S}$ 值を得ることができる。

平面の基質上に不均一に色素が存在する場合, 従来の 機器では反射光から間接的に色素の濃度に関するパラメ 一夕を得ることができなかったが，本方法を用いれば， Kubelka-Munk 関数式 $2 か ゙$ 成立する漫度範囲においては 容易に反射光画像から色素湄度に関する情報を得ること ができる。そして，一定の画像領域において K/S 值画 像を積分することによって，その領域内の色素秷量 $\Sigma K / S$ を定量することが可能となる。

そこで，色素濃度の定量の精度を検討するために，基 質上に種々の濃度の色素水溶液を種々のサイズにスポッ トし、PIAS-IIEを用いて、それらの K/S 画像から色素 濃度の定量を試みた。すなわち，色素の最大吸収波長と 同じ波長の分光フィルターを装着したモノクロビデオカ メラで, 色素スボットの反射光画像を取り込み，式1に

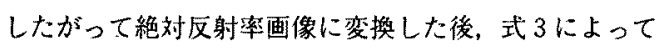
$\mathrm{K} / \mathrm{S}$ 画像に変換した。さらに，色素の無い基質について も同様に K/S 画像を得, サンプル画像から画像間の引 算によって基質のみの $\mathrm{K} / \mathrm{s}$ 値を差し引いたのち，画像 全体について積分することによって，スポットの総色素 壁のバラメータ $\mathrm{K} / \mathrm{S}$ を得た。

図 8 は精製したC.I. Acid Orange 7 を用いて，ペーパ 一クロマト用ろ紙上に種々の水溶液濃度で種々のサイズ のスポットをつくり，その画像の $\mathrm{K} / \mathrm{S}$ をスポットした 色素量に対してプロットしたものである。図8からわか

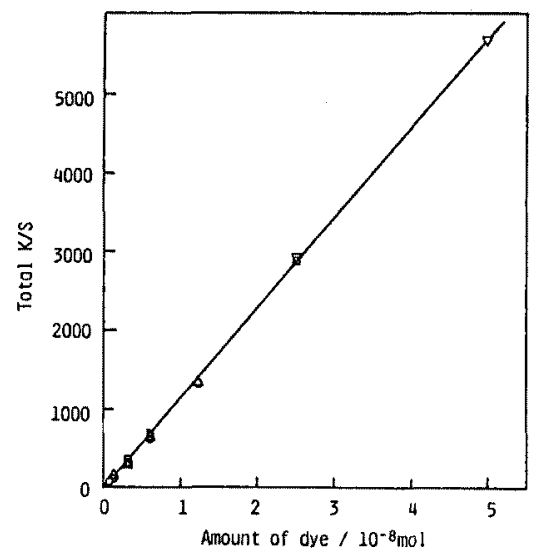

Fig. 8. Relation between amount of C. I. Acid Orange 7 on, filter paper and integrated $\mathrm{K} / \mathrm{S}$ value from $\mathrm{K} / \mathrm{S}$ image. Concentrations of dye stock solutions to prepare the dye spots were: $(O) 1.25 \times 10^{-4} \mathrm{~mol} / \mathrm{L}_{i}(\triangle) 2.5 \times 10^{-4}$ $\mathrm{mol} / \mathrm{L} ;(\square) 5.0 \times 10^{-4} \mathrm{~mol} / \mathrm{L} ;(\nabla) 1.0 \times 10^{-3} \mathrm{~mol} / \mathrm{L}$. 


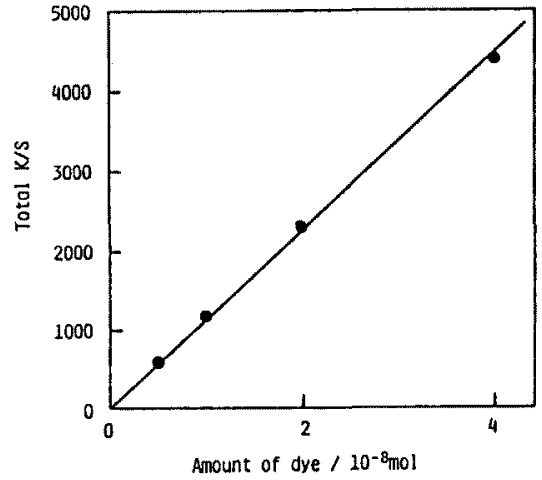

Fig. 9. Relation between amount of C. I. Acid Orange 7 on silica gel plate and integrated $\mathrm{K} / \mathrm{S}$ value from $\mathrm{K} / \mathrm{S}$ image. The concentration of dye stock solution to prepare the dye spots was $2 \times 10^{-3} \mathrm{~mol} / \mathrm{L}$.

るように、万紙上の Acid Orange 7 の量と画像の $\Sigma \mathrm{K} / \mathrm{S}$ との間には極めて良好な直線関係がある。低い色素湄度 の水溶液から大きなサイズのスポットをした試料と，高 い色素漕度の水溶液から小さなサイズのスポットをした 試料とを比較しても，その総色素量が同じであれば，正 確に同じ $\mathrm{K} / \mathrm{S}$ 值が得られていることがわかる。

同様の検討をシリカゲル薄層板を基質に用いて行なっ たのが图 9 である。同様にスポットの色素棇量と画像の $\Sigma_{K} / S$ との間には，スポットサイズ，形などに関係なく 良好な直線関係が得られている。

このような，画像による色素の定量法は，他の機器で は困難であったもので，裁維上の色素や污れの定量に有 効な手段となることが期待できる。前項で述べた分光反 射スベクトル，および色彩のパラメータの情報とを総合 すれば，基質上の色素に関する極めて多くの知見が，分 光画像を取り込むことによって一括して得られる。

\section{4. 繶括}

コンピュータ面像処理装置を㐫用した二次元的な色彩 管理システムとして，応用範用が広く高い精度の期待で きる分光反射率測定式画像測色システムを検討した。本 システムについて，着色ケント紙を用いて䋓対反射率を 測定した結果，分光光度計による測定結果と非常に良い 一致を示した。。また，三刺激値 X，Y，Zを算出し比較 したところ，本システムは十分な精度を有することがわ かった。

さらに，本システムが画像全体に拉いて正確なスべタ トル反射率を与えことを利用して，Kubelka-Munk関 数により，紙なとの基質上に存在する色素の量を定量す る試みを行った。その結果, 非常に精度の高い定量䊅果 が得られた。

従って，画像処理装置を測色に応用することによって スポットのみならず二次元的なスペクトルの変化にも对 応できる新しい色彩管理システムの可能性が示された。

付記：本研究の一部は第31回染色討論会 (1989, 東京) で発表した。

\section{文献}

1. 寺主一成，染色工業，35，413 (1987)

2. 德永 隆, 染色工業, 35, 414 (1987)

3. 片平春夫, 山田店行, 染色工業, 35，420（1987）

4. 鈴鹿正和. 染色工業, 35，430（1987）

5. 寺主一成, 「色材色彩工業」, 色染社，(1984)

6. 田川由利香, 上田充夫, 平崷恒亮, 轹消誌, 30 , 355 (1989)

7. 日本色彩学会編, 「色彩科学ハンドブック」, 東京大 学出版会, 756 (1980)

8. 日本工業規格 JIS Z 8701-1981，2 視野 XYZ 表色系 による色の表示方法

9. P. Kubelka, F. Munk, Z. Tech. Physik, 12, 593 (1931) 